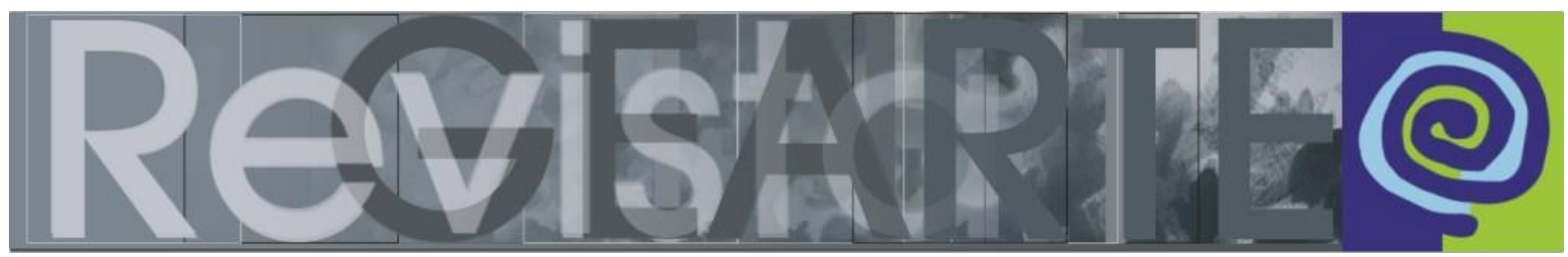

e-ISSN 2357-9854

\title{
Para onde caminha o ensino das Artes Visuais?
}

\author{
Sonia Tramujas Vasconcellos (Universidade \\ Estadual do Paraná - UNESPAR, Curitiba/PR, Brasil) \\ Karine Storck (Universidade Federal do Rio Grande \\ do Sul - UFRGS, Porto Alegre/RS, Brasil) \\ Daniel Bruno Momoli (Universidade do Alto Vale \\ do Rio do Peixe - UNIARP, Caçador/SC, Brasil)
}

\begin{abstract}
RESUMO - Para onde caminha o ensino das Artes Visuais? - Em 2016 completaram-se 20 anos da promulgação da Lei de Diretrizes e Bases da Educação que reconheceu a arte como uma área de conhecimento específica e assegurou-a enquanto um componente curricular obrigatório em todos os níveis da educação básica. Contudo, algumas fissuras foram abertas diante de um movimento para a criação de uma Base Nacional Comum Curricular (BNCC) e de Reforma do Ensino Médio. Tais situações colocaram a arte enquanto subárea do currículo e de caráter optativo na etapa do ensino médio. Quais os possíveis efeitos de tais mudanças para a formação docente e escolar em arte? De que modo essas resoluções se constituem como uma perda histórica para o ensino da arte? Neste texto apresentamos um conjunto de reflexões sobre as mudanças ocorridas no cenário educacional para situar e ampliar as discussões sobre a concepção de ensino e aprendizagem presente nesses documentos e que adentra os espaços escolares e a formação docente em arte.
\end{abstract}

PALAVRAS-CHAVE

Ensino das Artes Visuais. BNCC. Reforma do Ensino Médio.

RESUMEN - ¿A dónde camina la enseñanza de las Artes Visuales? - En 2016 se cumplieron 20 años de la promulgación de la "Lei de Diretrizes e Bases da Educação" que reconoció el arte como área de conocimiento específica e instituyó como componente curricular obligatorio en todos los niveles de la educación básica. Pero, esta garantía se ha deshecho ante la creación de una "Base Nacional Comum Curricular" (BNCC) y de la "Reforma do Ensino Médio". Tales situaciones colocaron el arte como subárea del currículo y de carácter optativo en la educación secundaria. ¿Cuáles son los posibles efectos de tales cambios para la formación docente y escolar en arte? ¿De qué modo estas resoluciones son una pérdida histórica para la enseñanza del arte? Acá presentamos algunas reflexiones sobre los cambios ocurridos en el escenario educativo para situar y ampliar las discusiones sobre la concepción de enseñanza y aprendizaje presente en esos documentos y que adentra los espacios escolares y la formación docente en arte.

PALABRAS CLAVE

Enseñanza de las Artes Visuales. BNCC. Reforma de la Educación Secundaria.

\section{O que nos (des)ampara}

\section{O segundo parágrafo $(\S 20)$ do Art. 26 da Lei de Diretrizes e Bases da}

Educação Nacional/LDB 9.394/1996 é continuamente invocado por nós, professores, pesquisadores e estudantes dos cursos de Licenciatura em Artes Visuais, e também

\footnotetext{
VASCONCELLOS, Sonia Tramujas; STORCK, Karine; MOMOLI, Daniel Bruno.

Para onde caminha o ensino das Artes Visuais? 
das Licenciaturas em Música, Teatro e Dança, além dos ecos e ressonâncias feitos nos cursos de Pedagogia. Isto porque foi a partir dessa LDB que se instaura o termo Ensino da Arte e não mais Educação Artística ${ }^{1}$. Ainda que a versão aprovada no documento pouco reflita as especificidades das linguagens artísticas, demarcou um território que possibilitou na primeira década dos anos de 2000 a aprovação das diretrizes para os cursos de graduação em artes visuais, dança, música e teatro.

Nosso entusiasmo pelo texto na Lei foi alimentado pelo árduo trabalho empreendido durante uma década: de 1987, quando é criada a Federação de Arte Educadores do Brasil/FAEB até o ano de 1996 quando a referida lei foi assinada e instituiu a obrigatoriedade do ensino da arte em todos os níveis de ensino. O texto da lei foi simplificado, sofreu cortes, mas possibilitou visibilidade e garantia da arte como área de conhecimento. No entanto, sabemos que tal proposição não ganhou concretude em todos os estados e municípios. Ainda enfrentamos a herança da formação polivalente ${ }^{2}$ nos materiais didáticos e nos currículos de arte; a falta de cursos de graduação nas áreas específicas: artes visuais, dança, música e teatro em diversos estados brasileiros; a contratação por parte de diversas secretarias de educação de profissionais sem a formação específica para atuar no ensino de arte; a manutenção de equívocos na interpretação da lei que dificultam a nomeação de profissionais formados nas distintas linguagens artísticas e tantas outras situações que ainda restringem e dificultam o acesso à arte com qualidade em todos os níveis de ensino.

A inserção da arte como conhecimento e conteúdo obrigatório nos diversos níveis da educação básica se relaciona com diversos fatores, entre eles a criação e expansão dos cursos de graduação e de pós-graduação, a constituição de um campo de pesquisa específico de ensino de arte, o fortalecimento das associações de educação e de arte - com destaque para as associações regionais e federal de arte educadores -, e a promulgação em 1996 da LDB. Um ato normativo que vincula o

1 A modificação desta terminologia envolve uma mudança epistemológica, teórica e política. Para mais informações consultar Barbosa (2003).

2 Cursos de Licenciatura em Educação Artística ofertados durante as décadas de 1970-80 e que abordavam as quatro linguagens (artes visuais, dança, música e teatro), habilitando o profissional a atuar com as quatro linguagens nas aulas de arte. Formação combatida pelos arte educadores e alterada na maioria das intuições de ensino superior neste século XXI. 
processo educativo à liberdade de aprender, de pesquisar, de acesso à cultura, ao pensamento, à arte e ao saber para todas as crianças a partir dos 4 anos.

Essas conquistas, entretanto, estão sendo rasuradas, escamoteadas. Nos parágrafos referentes ao ensino da arte na LDB, a redução e o esfacelamento são colocados em visibilidade pelas mudanças feitas nos últimos anos:

$\S 20$ O ensino da arte constituirá componente curricular obrigatório, nos diversos níveis da educação básica, de forma a promover o desenvolvimento eultural dos alunos.

$\S 2^{\circ}$-O ensino da arte, especialmente em suas expressões regionais, constituirá componente curricular obrigatório nos diversos níveis da educação básica, de forma a promover o desenvolvimento cultural dos alunos. (Redação dada pela Lei no 12.287, de 2010)

$\S 20$ O ensino da arte, especialmente em suas expressões regionais, constituirá componente curricular obrigatório da educação infantil e do ensino fundamental, de forma a promover o desenvolvimento cultural dos alunos. (Redação dada pela Medida Provisória no 746, de 2016)

$\S 2^{\circ} \mathrm{O}$ ensino da arte, especialmente em suas expressões regionais, constituirá componente curricular obrigatório da educação básica. (Redação dada pela Lei no 13.415 , de 2017)

(...)

§ $6^{\ominus}$ - A música deverá ser conteúdo obrigatório, mas não exclusivo, do componente curricular de que trata o $\$ 2^{\circ}$-deste artigo. (Incluído pela Lei no 11.769, de 2008)

$\S 6^{\circ}$ As artes visuais, a dança, a música e o teatro são as linguagens que constituirão o componente curricular de que trata $0 \S 2^{\circ}$ deste artigo. (Redação dada pela Lei no 13.278, de 2016) (BRASIL, 1996) ${ }^{3}$

A escrita original do $\S 2^{\circ}$ do Art. 26 menciona que "o ensino da arte constituirá componente curricular obrigatório nos diversos níveis da educação básica, de forma a promover o desenvolvimento cultural dos alunos" (1996). Texto que inaugura e assegura a presença da arte como campo de conhecimento na educação básica, ainda que interpretado de formas diversas pelas secretarias e instituições de ensino. Consideramos que a nomenclatura genérica arte muitas vezes dificulta a atuação na formação específica do professor: artes visuais, dança, música ou teatro. Nesse sentido, em 2008 foi inserido ao Art. 26 o $\S 6^{\circ}$, evidenciando a música como "conteúdo obrigatório, mas não exclusivo, do componente curricular de que trata 0 §2 deste artigo." Muitas discussões advieram desta inserção, visto que a visibilidade da música

3 No texto optamos por manter as alterações e os respectivos grifos do $\S 20$ e $\S 60$ do Art. 26 da LDB, pois esse aspecto se constitui como uma materialidade que nos convoca a pensar no efeito político das mudanças na legislação e para o ensino da arte. 
não tornava visíveis as demais linguagens artísticas, o que acarretou nova alteração do parágrafo em 2016.

Entretanto, a alteração ocorrida em 2008 fez com que várias secretarias de educação (estaduais e municipais) se preocupassem em inserir um profissional da área da música em ao menos um ano de cada etapa da educação básica. Vale ressaltar que outras secretarias delegaram ao profissional já responsável pela disciplina de arte (com ou sem formação específica) a inclusão da música em seus conteúdos. Em 2010, a alteração trouxe acréscimos e a nova redação passou a explicitar que o ensino da arte constituirá componente curricular obrigatório nos diversos níveis da educação básica, "especialmente em suas expressões regionais".

É em 2016 que duas importantes alterações ocorrem: 1) a alteração da redação do $\S 60$ do art. 26 feita pela Lei $n^{\circ} 13.278$, nomeando "as artes visuais, a dança, a música e o teatro" como as linguagens que constituirão o componente curricular arte. A visibilidade das distintas linguagens artísticas foi considerada uma vitória pela FAEB e um importante passo para a efetivação das especificidades da arte no espaço escolar - mudança que também exige disposição para o diálogo para que não seja interpretada como um retorno da polivalência -; 2) a promulgação da Medida Provisória que altera o Ensino Médio e insere como disciplinas obrigatórias em todos os anos apenas a matemática, o português e o inglês. Questão que será debatida mais adiante.

Por fim, a modificação ocorrida em 2017 exclui as frases "de forma a promover o desenvolvimento cultural dos alunos" e "nos diversos níveis da educação básica". O que temos agora é um texto pífio que reduz o espaço e o papel da arte na escola ao subtrair conquistas importantes. Dado o histórico de lutas para a efetivação do ensino de arte na educação básica, bem sabemos que tais reformulações na legislação não são neutras, muito menos apartidárias, o que nos convoca a assumir atitudes diante de tais apagamentos em uma tentativa de reversão e contestação do atual texto.

De algum modo nosso trabalho é guiado por uma utopia: a de propiciar a todas as crianças e adolescentes que frequentam a escola o acesso à arte e à cultura. Um trabalho político que situa a escola como lugar de materialização de experiências VASCONCELLOS, Sonia Tramujas; STORCK, Karine; MOMOLI, Daniel Bruno. 248 Para onde caminha o ensino das Artes Visuais? Revista GEARTE, Porto Alegre, v. 5, n. 2, p. 245-258, maio/ago. 2018.

Disponível em: http://seer.ufrgs.br/gearte 
democráticas, lugar de exercício da cidadania, de percepção da diferença. Um espaço de encontro, de aprendizado, de fala e de escuta, imerso em possibilidades e oportunidades. A arte enquanto um campo de conhecimento, com suas especificidades, materialidades e políticas de representação, se constitui em todos os níveis da educação básica como uma plataforma de pensamento para problematizar as narrativas culturais, questionar a hegemonia, produzir aberturas para a pluralidade e a diferença ${ }^{4}$. No entanto diante do retrocesso é preciso questionar: como manter e ampliar esse campo de formação frente a uma concepção de base curricular que generaliza as linguagens artísticas e retira a sua obrigatoriedade em todos os níveis da educação básica?

\section{A BNCC: entre contextos e versões}

Na primeira década do século XXI foram aprovadas as Diretrizes Curriculares dos cursos de graduação. Também são referenciais importantes as Diretrizes Curriculares Nacionais da Educação Básica $(2013)^{5}$ e o Plano Nacional de Educação/PNE (2014 - 2024) $)^{6}$. A necessidade de uma base nacional comum para nortear e promover a equidade do ensino nas diversas regiões do Brasil foi anunciada na LDB de 1996 e retomada no PNE?

O início da primeira versão deste documento ocorreu em 2014, a partir da constituição de equipes para cada uma das áreas que compõem o currículo da educação básica nas diferentes etapas e modalidades de ensino ${ }^{8}$. Em relação a área de arte, esse primeiro desenho do documento provocou estranhamento e ampla discussão sobre o texto durante o XXV Congresso da Federação de Arte Educadores

4 Para compreender a maneira como temos pensado as diferentes relações entre a arte e seu ensino, sugerimos visitar o site $\mathrm{xxx}$

5 Ver mais em: http://portal.mec.gov.br/index.php?option=com_docman\&view=download\&alias= 13448-diretrizes-curriculares-nacionais-2013-pdf\&ltemid=30192

6 Ver mais em: http://www.observatoriodopne.org.br/uploads/reference/file/439/documentoreferencia.pdf

7 A indicação de uma base no PNE pode ser vista nas metas relacionadas à universalização do ensino fundamental (metas 2 e 3); na de avaliação e Índice de Desenvolvimento da Educação Básica/IDEB (meta 7) e na que se refere à formação de professores (meta 15).

8 Para saber mais sobre o início deste processo ver Macedo (2014). 
na cidade de Fortaleza, em 2015, principalmente pelo uso do termo subcomponente para nomear as linguagens de artes visuais, dança, música e teatro. Após diversos debates e a constituição de um grupo para análise do material, foi elaborado e protocolado um documento (ofício nº 06/2015/FAEB) no MEC e em diversos outros órgãos federais o qual apontava limitações no texto e solicitava participação, na forma de construção coletiva, do componente curricular Arte na versão definitiva da BNCC 9 .

O ofício foi assinado por cinco entidades - Federação de Arte Educadores do Brasil/FAEB, Associação Brasileira de Educação Musical/ABEM, Associação Brasileira de Pesquisa e Pós-graduação em Artes Cênicas/ABRACE, Associação Nacional de Pesquisadores em Dança/ANDA, Associação Nacional de Pesquisadores em Artes Plásticas/ANPAP - e solicitava a participação de representantes dessas instituições na reformulação do documento. A participação ocorreu na forma de encontros realizados em Brasília no ano de 2016 na tentativa de discutir e alterar partes da redação. A $2^{a}$ versão do documento foi apresentada e discutida nos estados e municípios, com escassa participação das associações de arte e educação e das instituições de ensino superior. Entretanto, a grande surpresa foi a apresentação em 2017 de uma nova versão da BNCC, a terceira ${ }^{10}$ que, em si, é um documento diverso dos anteriores.

Em roda de conversa ${ }^{11}$ organizada pela Associação Nacional de PósGraduação e Pesquisa em Educação/ANPED e a Associação Brasileira de Currículo/ABdC, ocorrida na Conferência Nacional Popular de Educação/CONAPE12 2018, a presidente da ABdC Inês Barbosa ressalta que a BNCC, de certa forma, nega

9 Para saber mais, acesse o Boletim FAEB 1/2016, disponível em: https://faeb.com.br/admin/upload/ files/-Boletim\%20Faeb_AU0303U00baltimo\%2009\%2007\%202016.compressed.pdf

10 A elaboração da BNCC foi iniciada no ano de 2014 em consonância com um processo de reestruturação de um Sistema Nacional de Educação. No entanto, entre a primeira e terceira versão da Base há uma mudança extrema no contexto nacional, do impeachment de Dilma Rousseff ao contestado governo de Michel Temer. Trata-se da construção de um documento e suas versões em contextos muito distintos.

11 Roda de conversa intitulada "Educação e democracia: desafios e resistências nas relações entre educação básica e ensino superior frente à BNCC e as mudanças na LDB pós golpe de 2016".

12 A CONAPE foi organizada por movimentos sociais e entidades educacionais após interferência direta do governo federal na composição do Fórum Nacional pela Educação/FNE. Para maiores informações, acesse: http://fnpe.com.br/conape2018/ 
e substitui as políticas curriculares anteriores e que eram políticas de formulação de diretrizes curriculares plurais para cada nível e modalidade de ensino. Essa negação é evidente ao propor uma centralização curricular que já fracassou em diversos países que implantaram bases curriculares de caráter nacional, como os Estados Unidos e a Austrália.

Para Inês Barbosa há duas fissuras que produzem um desvio do processo que vinha sendo construído: 1) uma concepção de educação que compreende o ato educativo no qual o ensino antecede à aprendizagem, sendo que os direitos de aprendizagem são, na verdade, o que um grupo define que deve ser aprendido; 2) uma concepção de currículo ultrapassada e vinculada a uma lista de conteúdos e objetivos. Cabe destacar que não existe $60 \%$ do currículo a ser construído por cada estado e município quando se trata de enfoque/concepção de ensino e aprendizagem. Retornamos a um modelo de ensino calcado em competências, com a inserção de objetivos operacionais (alfanuméricos) atrelados a uma ideia de que o currículo deve ser neutro e por isso distanciado das discussões de gênero e diversidade sexual ${ }^{13}$.

Instaura-se uma lógica perversa de responsabilização do professor alinhada a uma padronização do que deve ser ensinado, com repercussão no material didático ${ }^{14}$ a ser distribuído nas escolas públicas. Vera Peroni et al. (2017, p. 417-418) destaca que mais de $70 \%$ das matrículas na educação básica ocorre na rede pública e que a expansão da educação "é uma realidade no país, principalmente após o Fundeb"15 e a Emenda Constitucional que ampliou a obrigatoriedade da educação de 4 a 7 anos". O que temos é a disputa de um projeto de sociedade, de educação e que no momento

13 Na divulgação preliminar da terceira visão da BNCC a palavra gênero aparece em vermelho e na versão final é excluída do texto.

14 A área de artes passou a integrar o Programa Nacional do Livro Didático - PNLD, somente em 2015. A aprovação dos livros considerava uma série de critérios, entre os quais os estudos de gênero e a valorização dos direitos humanos. Entretanto, para o próximo edital, as universidades foram excluídas do processo de avaliação e os critérios anteriormente utilizados não serão mais considerados.

15 Fundeb é o Fundo de Manutenção e Desenvolvimento da Educação Básica e de Valorização dos Profissionais da Educação. É um conjunto de 27 fundos (um por cada estado e mais do Distrito Federal) que redistribui recursos para a educação básica. Para maiores informações, acesse: http://portal.mec.gov.br/fundeb 
atual se filia a diferentes processos de privatização do ensino público, com marcada implicação para a democratização da educação.

O que fazer? Discutir, propor, reagir, barrar esta padronização do ensino. $O$ Brasil há muito tem essa tendência em adotar modelos estrangeiros. A história do ensino de arte comprova isto em vários momentos ${ }^{16}$. Para Carlos Eduardo Ferraço ${ }^{17}$, o que temos é um "late adopter", uma adoção tardia de tendências vinculadas a objetivos padronizantes, competências e habilidades, avaliação em larga escala, e que têm sido questionadas em diversos países.

\section{Cadê a arte que estava aqui? A reforma do ensino médio}

O Ensino Médio (EM) passou a fazer parte da educação básica somente com a aprovação da LDB 9.394/1996 e desde então foram constituídos fóruns, observatórios e outros grupos qualificados para debater seu sentido educativo e formativo. Para Suzane Gonçalves (2017, p. 133), os diversos problemas relacionados ao EM, como "sua ressaltada falta de qualidade, as condições desiguais de oferta, os baixos índices nas avaliações externas", intensificaram as discussões sobre a necessidade de uma reforma para esta última etapa da educação básica. Mas a autora salienta, baseada em Krawczyk ${ }^{18}$, que não podemos deixar de lado que as deficiências atuais do EM são, em grande medida, expressões de uma presença tardia de um projeto de democratização da educação pública no nosso país.

A reformulação do ensino médio vinha sendo fomentada por determinadas políticas públicas como o Programa Ensino Médio Inovador (2009) e o Pacto Nacional pelo Fortalecimento do Ensino Médio (2013), ambos promovidos pelo MEC, e o Movimento Nacional pelo Ensino Médio (2014), criado por dez entidades do campo

16 A história do ensino da arte no Brasil, assim como a própria história da educação brasileira, é marcada pela adoção de modelos estrangeiros. Os jesuítas impuseram um modelo europeu de ensino e a Escola Imperial de Belas Artes instituiu o neoclássico em oposição ao barroco brasileiro. $\mathrm{Na}$ implantação da LDB 5.692/1971 foi assumido um modelo estadunidense de ensino via acordo MEC-USAID e na elaboração dos PCN's, na década de 1990, assumiu-se um modelo espanhol. Para ver mais consultar Barbosa (2015).

17 Participante da roda de conversa na CONAPE 2018 já mencionada neste texto.

18 KRAWCZYK, Nora. Reflexões sobre alguns desafios do Ensino Médio no Brasil hoje. In: Cadernos de pesquisa, v. 41, n. 144, p. 752-769, set./dez. 2011. 
educacional. Ações que envolviam instituições de ensino e associações educacionais na elaboração, execução e análise de propostas curriculares. Qual a necessidade então de se impor uma reforma?

Em setembro de 2016, após o impeachment da presidente Dilma Rousseff, é publicada a medida provisória 746 (transformada na Lei 13.415 em 2017). Uma proposição feita sem diálogo com a sociedade e que altera substancialmente o currículo do EM, a LDB e a lei que regulamenta o Fundeb. Nesta reforma, o ensino de arte se situa como "estudo e prática" - assim como as áreas de filosofia, sociologia e educação física -, destituindo seu espaço como área de conhecimento obrigatória na formação dos alunos. A obrigatoriedade de apenas três disciplinas em todos os anos do EM se situa como uma interrupção no processo de formação integral do aluno, reduzindo as possibilidades do jovem em acessar diversas formas de conhecimento e ampliar sua visão de mundo.

Portanto, que formação humana podemos vislumbrar nessa reforma chamada Novo Ensino Médio? O que o brilho da novidade está ofuscando? Se a atuação de professores com formação específica para ministrar arte era uma conquista em processo - assim como a atuação na sua linguagem de formação -, como isto será garantido sem a obrigatoriedade do ensino da arte em todos os níveis de ensino? Como ficam os cursos de licenciatura em artes visuais, dança, música e teatro neste cenário?

De acordo com Dante Henrique Moura (2010), na gênese da LDB de 1996 já estava presente a discussão sobre a concepção e os princípios norteadores do ensino médio. De um lado tínhamos a defesa por uma educação integrada à formação profissional e, de outro, a separação entre educação básica e formação profissional.

Na proposta de integração, o ensino médio não seria profissionalizante no sentido stricto, - formar para uma profissão específica, mas estaria orientado à recuperação da relação entre conhecimento e prática do trabalho, o que demandaria explicitar como a ciência se converte em potência material no processo produtivo. (MOURA, 2010, p. 2) 
Estudos posteriores, como o ensino médio integrado ${ }^{19}$, concebiam essa etapa da educação "a partir de uma base unitária, fundamentada na integração entre trabalho, ciência, tecnologia e cultura" (2010, p. 4). Ainda que uma crítica recorrente até então fosse a oferta de "conteúdos das ciências, das letras e artes, sem diálogo com a tecnologia, com a cultura e com a realidade do mundo do trabalho" (MOURA, 2010, p. 5), é preciso e necessário que mudanças ocorram de maneira a ampliar e fortalecer uma educação básica comum para todos os estudantes e não o contrário.

O que nos interessa salientar aqui é o modo como essa integração (ou falta de) aparece nesse novo desenho de ensino médio, no qual $40 \%$ da carga horária podem ser feitas a distância já no primeiro ano. Além disto, diversas áreas do conhecimento se situam como estudos e práticas e não como disciplinas ou componentes curriculares obrigatórios. A reforma do EM, e de modo mais ampliado a BNCC, interrompe uma prática escolar que permite às crianças e aos jovens o acesso à diversidade das produções culturais, e não apenas às hegemônicas, envolvendo a arte brasileira, da cultura latino-americana, da produção de mulheres, de negras e negros, de indígenas, da cultura popular. Como apresentar e discutir essa diversidade em um EM restrito a estudos e práticas que podem ou não serem oferecidos ao estudante $^{20}$ ? Defendemos aqui que é na escola (mas não somente), que crianças e jovens têm a chance de conhecer e discutir o patrimônio material e imaterial, local e nacional, assim como produzir, experienciar e divergir. É este acesso qualificado que propicia contato, percepção, conhecimento, identidade, voz e alteridade.

\section{A luta não cessa: necessitamos enfrentar, resistir e transformar}

Estamos diante de um movimento reducionista e que reforça as desigualdades na educação. Seja pela divisão entre as disciplinas e os estudos e práticas, estas envolvendo a área de humanas e artes no EM; seja no formato descritivo e alfanumérico dos objetivos de cada área do saber na BNCC; seja no fatiamento do

19 Esta modalidade de EM integrado à educação profissional defendia que os conteúdos do Ensino Médio e da formação profissional deveriam ser trabalhados de forma integrada durante todo o curso. Esta modalidade é ofertada principalmente nos Institutos Federais de Educação.

20 As instituições de ensino podem oferecer de 1 a 5 percursos formativos. Ou seja, poderá haver apenas uma opção de formação.

VASCONCELLOS, Sonia Tramujas; STORCK, Karine; MOMOLI, Daniel Bruno. 
currículo em cinco itinerários formativos. Nega-se o direito a uma formação básica comum e em contrapartida as redes de ensino é que irão decidir que itinerários poderão ser cursados pelos estudantes. Junto a isto temos o reconhecimento do "notório saber", a atuação docente de pessoas sem formação específica, além de outras propostas de flexibilização. Para quem estas mudanças serão benéficas?

Atrelado a esta concepção de educação temos uma espécie de Base Nacional de Formação Docente. Uma forma de indução que insere no currículo das licenciaturas outro modelo de trajetória formativa se estas quiserem aderir ao Programa Institucional de Bolsas de Iniciação à Docência (Pibid) e de Residência Pedagógica (RP). Inferência que envolve adequações das propostas pedagógicas dos cursos às orientações da BNCC entre outras normativas. O que se vislumbra é uma política autoritária e uma intervenção na autonomia política, curricular e didática das instituições de ensino superior ${ }^{21}$.

Mais do que ver o que se passa hoje em termos de mudanças da legislação, na elaboração de novos documentos referenciais, na implementação de novas políticas por vias de reformas, nas alterações e cortes nos programas e incentivos educacionais, precisamos estar atentos ao projeto de sociedade que tais medidas representam e seus possíveis efeitos. A ampliação do número de professores de arte com formação específica só ocorreu nos últimos anos a partir de muitas lutas, envolvendo alteração de leis, expansão das universidades públicas, dos institutos federais de educação, aumento da oferta das licenciaturas (em artes visuais, dança, música e teatro) e a interiorização de instituições de ensino. Avanços carregados de embates e reivindicações para que a disciplina de arte seja ministrada por um profissional habilitado e que este possa atuar na especificidade de sua formação.

Ainda que a BNCC do ensino fundamental situe a arte como área de conhecimento, como componente curricular composto por distintas linguagens - artes visuais, dança, música e teatro -, essas linguagens são reduzidas a unidades

21 A ANPEd apresentou um documento em audiência do CNE em 09 de abril de 2018 questionando o teor dos editais do Pibid e RP. Disponível em: https://avaliacaoeducacional.files.wordpress. com/2018/04/formacaoprofessores_anped_final.pdf 
temáticas neste mesmo documento. Já no ensino médio, a arte se dilui nas linguagens e suas tecnologias, envolvendo língua portuguesa, arte e educação física. As especificidades das linguagens artísticas desaparecem. Com exceção da língua portuguesa, as demais linguagens se aglutinam e se restringem a sete competências específicas e suas respectivas habilidades.

A repercussão desses apagamentos no ensino de arte em um curto período do tempo poderá ser vista na diminuição da procura pelos cursos de licenciatura em artes visuais, dança, música e teatro. O que levaria uma/um jovem, a escolher um curso superior com pouco espaço e reduzida legitimidade de atuação? É possível citar ainda o amortecimento do movimento pela expansão do número de professores com formação específica em arte na educação básica, tendo em vista a dificuldade em exigir das secretarias (municipais e estaduais) o cumprimento da Lei sobre a atuação do professor formado na área. O mesmo poderá ocorrer com os concursos públicos.

Consideramos que escrever é também uma forma de resistência que nos permite ampliar as significações frente às alterações na legislação e suas consequências na reforma do ensino médio, na BNCC e nos editais do Programa Institucional de Bolsas de Iniciação à Docência (Pibid) e de Residência Pedagógica (RP). As reflexões apontadas neste texto evidenciam posicionamentos segregacionistas e reducionistas na formação escolar. Precisamos resistir. Se nos sentimos desamparados diante das perdas, urge fortalecer as formas coletivas de enfrentamento: retomar os movimentos regionais; realizar trocas e partilhas entre professores; ampliar a participação e voz nas discussões com as escolas, com as secretarias e núcleos, com o Ministério da Educação. É preciso intensificar a presença nos fóruns, nos eventos, nos congressos, para discutir, analisar e fortalecer o ensino de arte. A atuação diária e qualificada como professores de arte é a nossa força. É o que nos permite resistir e lutar para a manutenção da arte nas suas especificidades em todos os níveis de ensino, atrelada ao pensamento crítico, à pluralidade cultural e à formação ética, estética e política. 


\section{Referências}

BARBOSA, Ana Mae. Inquietações e mudanças no ensino da arte. 2 ed. São Paulo: Cortez, 2003.

BARBOSA, Ana Mae. Redesenhando o desenho: educadores, política e história. São Paulo: Cortez, 2015.

BRASIL. Lei no 13.005/2014 - Plano Nacional de Educação 2014-2024: Disponível em: http://www.observatoriodopne.org.br/uploads/reference/file/439/documento-referencia.pdf Acesso em: 31 de maio de 2018.

BRASIL. Lei № 9.394/1996 - Lei de Diretrizes e Bases da Educação Brasileira. Disponível em: http://www.planalto.gov.br/ccivil_03/LEIS/L9394.htm Acesso em: 31 de maio de 2018.

BRASIL. Base Nacional Comum Curricular, 2018. Disponível em: http://basenacionalcomum.mec.gov.br/ Acesso em: 20 de maio de 2018.

GONÇALVES, Suzane da R.V. Interesses mercadológicos e o "novo" ensino médio. Revista Retratos da Escola, Brasília, v. 11, n. 20, p. 131-145, jan./jun. 2017.

MACEDO, Elizabeth, Base nacional curricular comum: novas formas de sociabilidade produzindo sentidos para educação. Revista e-Curriculum, v. 12, n. 3, out. dez., 2014, p. 1530-1555. Disponível em: http://www.redalyc.org/articulo.oa?id=76632904006 Acesso em: 31 de maio de 2018.

MOURA, Dante Henrique. Algumas possibilidades de organização do ensino médio a partir de uma base unitária: trabalho, ciência, tecnologia e cultura. In: SEMINÁRIO NACIONAL CURRÍCULO EM MOVIMENTO: PERSPECTIVAS ATUAIS, 1, 2010, Belo Horizonte. Anais... Belo Horizonte, novembro de 2010, p. 1-14. Disponível em: http://portal.mec.gov.br/docman/dezembro-2010-pdf/7177-4-2-

algumas-possibilidades-organizacao-ensinomedio-dante-henrique/file Acesso em: 12 de maio de 2018.

PERONI, Vera; CAETANO, Maria Raquel; LIMA, Paula de. Reformas educacionais hoje: as implicações para a democracia. Revista Retratos da Escola, Brasília, v.11, n. 21, p. 415-432, jul./dez. 2017.

\section{Sonia Tramujas Vasconcellos}

Mestre e Doutora em Educação pela Universidade Federal do Paraná/UFPR $(2007$; 2015) com estágio de doutoramento na Northern Illinois University (fomento CAPES). Graduada em Educação Artística (UFPR, 1982) e em Pintura (EMBAP, 1987), com especialização em Filosofia da Educação (PUCPR, 1988). Professora adjunta da Universidade Estadual do Paraná/UNESPAR, atuando no Curso de Licenciatura em Artes Visuais da Faculdade de Artes do Paraná/FAP. Líder do grupo de pesquisa Arte, Educação e Formação Continuada/GAEFO da UNESPAR e integrante do ARTEVERSA, grupo de estudo e pesquisa em arte e docência da UFRGS. É membro da ANPAP, da ANPEd e da FAEB (com participação na gestão 2015-2016).

E-mail: soniatvasconcellos@gmail.com

Currículo: http://lattes.cnpq.br/7124035497111005

\section{Karine Storck}

Mestra em Educação pela Universidade Federal do Rio Grande do Sul - UFRGS (2015) e especialista em Os Estudos Culturais e os currículos escolares contemporâneos da Educação Básica pela mesma universidade (2013). Graduada em Licenciatura em Artes Visuais pela UFRGS (2011). Desde 2017 atua como professora de artes visuais no Colégio de Aplicação da UFRGS. É integrante do ARTEVERSA - Grupo de estudo e pesquisa em arte e docência (UFRGS).

E-mail: karinestorck@gmail.com

Currículo: http://lattes.cnpq.br/2263765680250381

VASCONCELLOS, Sonia Tramujas; STORCK, Karine; MOMOLI, Daniel Bruno. 


\section{Daniel Bruno Momoli}

Mestre em Educação pela Universidade Federal do Rio Grande do Sul - UFRGS. Especialista em Educação Interdisciplinar pelo Instituto de Desenvolvimento do Alto Uruguai - IDEAU. Graduado em Licenciatura em Artes pela Universidade do Oeste de Santa Catarina. É Professor das áreas de teorias e ensino das artes na Universidade do Alto Vale do Rio do Peixe - UNIARP em Caçador e da Faculdade SENAC. É membro dos Grupos de Pesquisa Arte na Pedagogia-GPAP (Mackenzie); ARTEVERSA Grupo de estudo e pesquisa em arte e docência (UFRGS). Além de atuar como pesquisador voluntário do Grupo Pensu: estudo e pesquisa sobre ensino superior.

E-mail: momoli.daniel@gmail.com

Currículo: http://lattes.cnpq.br/7701594143194418

Recebido em 31 de maio de 2018

Aceito em 15 de julho de 2018 